\title{
EL PRINCIPIO \\ DE NO REGRESIVIDAD \\ DE LOS DERECHOS SOCIALES \\ EN EL ORDENAMIENTO \\ CONSTITUCIONAL ESPAÑOL
}

MIGUEL AGUDO ZAMORA 
SUMARIO

1. ESTADO, SOLIDARIDAD Y COHESIÓN SOCIAL. 2. APUNTES DOCTRINALES Y JURISPRUDENCIALES SOBRE EL PRINCIPIO DE NO REGRESIVIDAD DE LOS DERECHOS SOCIALES. 3. LÍMITES A LA REGRESIVIDAD DE LOS DERECHOS SOCIALES. a) Límites derivados del ordenamiento internacional. b) Límites derivados de la dignidad como contenido esencial de los derechos sociales. c) Límites derivados de la prohibición de la arbitrariedad: la necesidad de una suficiente motivación. 4. A MODO DE CONCLUSIONES: REFORMA CONSTITUCIONAL Y NO REGRESIVIDAD DE LOS DERECHOS SOCIALES. 


\title{
EL PRINCIPIO \\ DE NO REGRESIVIDAD \\ DE LOS DERECHOS SOCIALES EN EL ORDENAMIENTO CONSTITUCIONAL ESPAÑOL ${ }^{1}$
}

\author{
MIGUEL AGUDO ZAMORA* \\ Catedrático de Derecho Constitucional \\ Universidad de Córdoba
}

\section{ESTADO, SOLIDARIDAD Y COHESIÓN SOCIAL}

Nuestra Constitución define a España como un Estado social ${ }^{2}$. La Nación española, en 1978, decide pues como colectivo constituirse en una modalidad de

\footnotetext{
${ }^{1}$ Este trabajo se enmarca en el Proyecto de Investigación «Constitución financiera vs. Constitución social. Redefinición del Estado Autonómico y Social a la luz de la cláusula de estabilidad presupuestaria». Código: DER2013-48327-C3-3-R.

* Catedrático de Derecho Constitucional. Universidad de Córdoba. Facultad de Derecho y Ciencias Económicas y Empresariales. C/Puerta Nueva s/n., 14071 Córdoba (España). ORCID 0000-0003-1378-4708. E-mail: miguelagudo@uco.es.

${ }^{2}$ Utilizando la clásica definición de Briggs, podemos definir, pues, el Estado social o de bienestar como «el poder organizado y usado deliberadamente a través de la política y la administración en un esfuerzo para modificar el juego de las fuerzas del mercado al menos en tres direcciones: primera para garantizar a los individuos y familias una renta mínima independientemente del valor de mercado de su trabajo o su propiedad; segundo, reducir la amplitud de la inseguridad para facilitar a individuos y familias satisfacer ciertas contingencias sociales (por ejemplo, enfermedad, vejez y desempleo) que de lo contrario conducen a crisis individuales y familiares; y, tercero, para asegurar que a todos los ciudadanos sin distinción de status o clase les sean ofrecidos los mejores estándares disponibles en relación a cierta gama acordada de servicios sociales» (BRIGGS, A. (1961) «The welfare state in historical perspective», European Journal of Sociology, Cambridge Univ. Press).
} 
organización del poder político que comporta una responsabilidad de los poderes públicos en orden a asegurar una protección social y un bienestar básico para los ciudadanos, que se caracteriza por incluir los derechos sociales dentro de la categoría de los derechos de ciudadanía, perseguir la igualdad efectiva entre los ciudadanos y dotarles de seguridad económica y servicios sociales.

Supone, pues, la provisión pública de una serie de servicios sociales, incluyendo transferencias para cubrir las necesidades humanas básicas de los ciudadanos en una sociedad compleja y cambiante y la responsabilidad estatal en el mantenimiento de un nivel mínimo de vida a todos los ciudadanos pertenecientes a la comunidad política ${ }^{3}$. En ese sentido, Heller considera que «el sentido del Estado solo puede ser su función social, es decir, la misión que tiene que cumplir como factor, como unidad de acción en la conexión de la actividad social» ${ }^{4}$. El Estado social se responsabiliza, por lo tanto, de la procura existencial, concepto acuñado por Forsthoff y que supone, como señala García Pelayo, la responsabilidad por parte del Estado «de llevar a cabo las medidas que aseguren al hombre las posibilidades de existencia que no puede asegurarse por sí mismo» ${ }^{5}$.

Nuestra Constitución se puede encuadrar, pues, en el llamado constitucionalismo social tardío de los pasados años 70 junto a la Constitución portuguesa de 1976 y la griega de $1975^{6}$. Se caracteriza por la constitucionalización formal del principio del Estado social en el primer artículo de la Constitución, que expresa la voluntad de la nación española de construir y desarrollar un sistema económico de compromiso entre las fuerzas económicas enfrentadas, esto es, el capital y el trabajo; entre el mercado, la libre competencia y los derechos sociales. La nuestra, como señala Font Galán ${ }^{7}$, es una Constitución económica tensionada por esos dos vínculos aparentemente enfrentados, pero que, en cuanto constitucionalizados, tienen necesariamente que compatibilizarse.

3 Monereo Perez, J. L. (1996) Derechos sociales de la ciudadanía y ordenamiento laboral. Madrid, Consejo Económico y Social, pp. 25 y ss.

${ }^{4}$ Heller, H. (1974) Teoría del Estado. México, Fondo de Cultura Económica, p. 123.

5 García Pelayo, M. (1982) Las transformaciones del Estado contemporáneo. Madrid, Alianza Editorial, 1982

6 Es amplísima la bibliografía que se podría citar sobre el Estado social y la evolución del constitucionalismo, pero destacamos por la conjunta capacidad de síntesis y de análisis de una materia tan extensa como apasionante a TORRES DEL MORAL, A. (2014) «El Estado social y la evolución del constitucionalismo social», en Terol Becerra, M. y Jimena Quesada, L. (dirs.) Tratado sobre protección de derechos sociales, Valencia, Tirant lo Blanch, p. 29 y ss.

7 Font Galan, J. I. (2014) «Apogeo de racionalidad económica y disenso constitucional. Una reflexión constitucional», Revista de Fomento Social, n. ${ }^{\circ} 275$, p. 249 y ss. 
Tal como señala este autor, nuestra Constitución formal refleja claramente el espíritu del consenso socialdemócrata o keynesiano de posguerra: de un lado, el Estado social (razón social) (art. 1.1) y, de otro, la economía de mercado (razón económica) (art. 38). Pero es preciso indagar más de cerca los términos de esa conciliación de racionalidades y modelos socioeconómicos.

La Constitución se abre con un Preámbulo en el que se habla de la justicia, la libertad, el bien común, el orden económico y social justo, la digna calidad de vida y de una sociedad democrática avanzada. Continúa en el artículo 1.1 proclamando el establecimiento formal del Estado social, y en el artículo 9.2 vincula esta forma de Estado a la Constitución económica material para garantizar así, en contraste con lo sucedido en el Estado liberal, que la libertad y la igualdad de los individuos y de los grupos en que se insertan serán reales y efectivas, y no meramente formales, asegurando así su disfrute en plenitud. Por lo tanto, la conjunción de estos dos preceptos constitucionalizan formalmente el núcleo del vínculo social de la Constitución económica; esto es, la racionalidad social del sistema económico constitucional. Incluso puede añadirse que el artículo 9.2 obliga a los poderes públicos a materializar real y efectivamente ese «vínculo social» con las políticas económicas y sociales diseñadas en el capítulo III del título I ( DDe los principios rectores de la política social y económica», arts. 39 a 52) y de conformidad con las atribuciones y pautas avanzadas establecidas en el título VII («Economía y Hacienda», arts. 128 a 131) pues aquí se encuentran las bases y directrices de la llamada Constitución económica material que los poderes públicos están obligados a programar y ejecutar; aunque es cierto, como recuerda la doctrina que esta obligación y esta responsabilidad solo se impone como criterio político y, por tanto, sin garantizar su efectivo cumplimiento a los poderes públicos ${ }^{8}$. Sobre esta idea de la racionalidad social del sistema económico constitucional volveremos posteriormente al hablar de sostenibilidad social y al fijar los límites a las medidas normativas que impliquen regresividad en el contenido, eficacia y protección de los derechos sociales.

El modelo social de nuestra Constitución implica también el reconocimiento de derechos económicos y sociales ${ }^{9}$ siguiendo con una pauta de comporta-

${ }^{8}$ Font Oporto, P. (2012) «Ruptura del consenso socialdemócrata y crisis del modelo de Estado». Revista de Fomento Social, núm. 266, p. 211 y ss.

9 Bajo esta denominación, se identifica un grupo de derechos caracterizado fundamentalmente por el momento histórico de su reconocimiento. Estos derechos son el producto de las reivindicaciones obreras de los Estados industrializados de la segunda mitad del siglo xix. Por eso se les denomina también derechos de segunda generación, surgidos tras los derechos civiles y políticos postulados por las revoluciones burguesas de finales del siglo XVIII y principios del siglo xIX en Europa y Norteamérica. La constitucionalización de los derechos sociales se produjo por vez pri- 
miento propia de derecho comparado ${ }^{10}$. El reconocimiento de estos derechos supone la plasmación constitucional de un principio axiológico que alumbra su reconocimiento: el principio de solidaridad. Tal como señala acertadamente Fernández Segado el principio de solidaridad se imbrica plenamente en el núcleo duro del Estado social aunque no todas las Constituciones de nuestro tiempo lo contemplen, pero ha de entenderse implícito en las Constituciones de contenido social pues «su estrecha conexión con los derechos económicos, sociales y culturales así lo ha venido a corroborar, dada la amplitud con que los códigos constitucionales actuales recepcionan estos derechos de naturaleza básicamente prestacional. Piénsese al respecto en la estrecha vinculación entre la dimensión material de estos derechos, que se manifiesta en la pertinente prestación, su dimensión axiológica, que vendría encarnada en los valores de la igualdad y la justicia, y el propio valor de la solidaridad, sin olvidar un nuevo vínculo que pondría en conexión determinados derechos de la tercera o cuarta generación, según las distintas caracterizaciones doctrinales, con lo que se ha dado en llamar la solidaridad intergeneracional (el derecho a un medio ambiente adecuado al desarrollo de la persona sería quizá el ejemplo paradigmático)» ${ }^{11}$.

Pero atendiendo a la vaguedad y uso polisémico de este concepto, que ha sido puesto de manifiesto por la doctrina ${ }^{12}$, y que por ejemplo en nuestro texto cons-

mera en la Constitución mexicana de Querétaro de 1917, en la alemana de Weimar de 1919 y en la española republicana de 1931, además de en las Constituciones de los Estados socialistas del bloque soviético. Pero, a partir de la Segunda Guerra Mundial, se generaliza el reconocimiento de estos derechos en las Constituciones democráticas.

También los Tratados internacionales reconocen, junto a los clásicos derechos civiles y políticos, derechos sociales. En el marco de Naciones Unidas, la Declaración Universal de Derechos Humanos de 1948 consagra el derecho a la seguridad social, al trabajo, a la protección en caso de paro, a igual salario y al descanso y tiempo libre. Igualmente, existe un Tratado expresamente establecido para el reconocimiento de estos derechos: el Pacto Internacional sobre Derechos Económicos, Sociales y Culturales, aprobado por la Asamblea General de las Naciones Unidas el 16 de diciembre de 1966.

También en los distintos ámbitos regionales se aprueban Tratados y Convenios sobre derechos fundamentales en general y derechos sociales en particular.

10 Para un estudio profundo sobre estos derechos se hace imprescindible la lectura de TEROL Becerra, M. (2012), «Treinta años de desarrollo constitucional y legislativo de los derechos sociales: derechos ciudadanos y principios rectores», en Derechos sociales y principios rectores (Coords. Cascajo Castro, J. L., Terol Becerra, M., Domínguez Vila, A., Navarro Marchante, V.), Valencia, Tirant lo Blanch, pp. 45 y ss. Resultan también de gran interés el resto de artículos de este libro que recoge las Actas del IX Congreso de la Asociación de Constitucionalistas de España, celebrado en Santa Cruz de Tenerife en enero de 2011.

11 Fernández Segado, F. (2012), «La solidaridad como principio constitucional», en Teoría y realidad constitucional $n .^{\circ} 30$, p. 153.

12 Pueden consultarse, entre otros, Solano SAntos, L. F. (2009), «La solidaridad social, objetivo último de las relaciones públicas», en Documentación de las Ciencias de la Información, 
titucional puede encontrarse en diversos preceptos al referirse a la solidaridad entre territorios a la hora de referirnos a la imbricación axiológica de los derechos sociales, además de referirnos al principio de igualdad y al de solidaridad, debemos resaltar su fundamentación en la búsqueda de la cohesión social, dándose el resultado que del mismo modo que la cohesión social fundamenta la necesidad del reconocimiento, eficacia y protección de los derechos sociales, igualmente la efectividad de estos derechos suponen el instrumento más poderoso para hacer real esta cohesión ${ }^{13}$.

Definir lo que es la cohesión social no es tarea fácil ${ }^{14}$. Quizá, y tal como señala Pérez Yruela ${ }^{15}$, la institución política que más ha hecho por la definición de cohesión social sea el Consejo de Europa.

vol. 32, 2009, pp. 267 y ss.; AMENGUAL, G. (1993) «La solidaridad como alternativa. Notas sobre el concepto de solidaridad», en Revista Internacional de Filosofía Política, n. ${ }^{\circ} 1 / 1993$, Enero 1993 , pp. 135 y ss.; Jiménez Redondo, J. C. (2010), El valor de la solidaridad en un mundo global, Madrid, CEU Ediciones; HAYWARD, J. E. S. (1959), «Solidarity: the Social History of an Idea in Nineteenth Century France», en International Review of Social History, vol. 4, n. ${ }^{\circ} .2$, pp. 261 y ss.; VidAL GIL, E. J. (1993), «Sobre los derechos de solidaridad. Del Estado liberal al social y democrático de Derecho», en Anuario de Filosofía del Derecho, tomo X, pp. 89 y ss.; Pérez Moreno, A. (1978), «Técnicas jurídicas garantizadoras del principio de solidaridad regional», en Estudios sobre el Proyecto de Constitución, Madrid, Centro de Estudios Constitucionales, pp. 703 y ss.; GaleotTi, S. (1996), «Il valore della solidarietà», en Diritto e Società, 1996/1, pp. 1 y ss.

${ }_{13}$ Por su parte, la Carta de los Derechos Fundamentales de la Unión Europea recoge en su capítulo IV, denominado Solidaridad, un elenco de derechos, muchos de ellos vinculados al ámbito laboral, así como otros relativos a la protección de la salud, acceso a los servicios de interés económico y general, protección del medio ambiente y de los consumidores. Para un estudio profundo de esta carta puede consultarse MANGas MARTín, A. (Dir) (2008), Carta de los derechos fundamentales de la Unión Europea. Comentario artículo por artículo. Bilbao, Fundación BBVA.

${ }_{14}$ Para un estudio profundo sobre esta cuestión, pueden consultarse, entre otras, las siguientes obras; CEPAL (2006), La cohesión social en los países desarrollados: conceptos e indicadores. Santiago de Chile, CEPAL; Comisión Europea (2007), La política de cohesión 2007-2013. Comentarios y textos Oficiales. Luxemburgo, Oficina de Publicaciones Oficiales de las Comunidades Europeas; EAsterley, W., Ritzen, J. y Woolcock, M (2006), «Social Cohesion, Institution and Growth», Economics E Politics, 18,2, pp. 103-120; Friedkin, N. H. (2004), «Social Cohesion», Annual Review of Sociology, 30, pp. 409-425; FundaCión LuIs Vives (2005), Cumbre de Lisboa. Estrategia Europea de Inclusión Social. Madrid, Fundación Luís Vives: Cuaderno Europeo 2; Garrido Yserte, R., Mancha Navarro, T. y Cuadrado Roura, J. R. (2007), «La Política Regional y de Cohesión en la Unión Europea: veinte años de avance y un futuro nuevo», Investigaciones Regionales, 10, pp. 239-266; PAHL, R. E. (1991), «The search for social cohesion: from Durkheim to the European Commission», Arch. Europ. Sociol. XXXII. pp. 345-360.

15 Pérez Yruela, M. (2012), Modelo de cohesión social en Europa ¿Aplicabilidad en América latina?. Instituto de Estudios Sociales Avanzados (IESA/CSIC) p. 16 y ss. 
En julio de 2010, el Consejo aprobó el documento denominado Nueva Estrategia y plan para la cohesión social ${ }^{16}$, que definía de este modo la cohesión social: «la capacidad de una sociedad para asegurar el bienestar de todos sus miembros — minimizando las diferencias y evitando la marginación - para gestionar las diferencias y las divisiones y asegurar los medios para lograr el bienestar de todos sus miembros. La cohesión social es un concepto político que es esencial para ligar los tres valores centrales del Consejo de Europa: los derechos humanos, la democracia y el imperio de la ley (Estado de Derecho)». En la posición del Consejo de Europa, tal como recuerda este autor destaca la inclusión del conflicto como parte de la vida social, su alejamiento de una posición centrada sobre todo en el consenso y su idea de la cohesión social como un equilibrio dinámico entre fuerzas centrífugas y centrípetas de la sociedad. Esto responde a la manera como se ha ido conformando la noción de cohesión social en la historia de las ideas en Europa. Igualmente hay que destacar la vinculación que se establece de la cohesión social con la democracia y el Estado de Bienestar: no hay genuina democracia —o democracia de calidad— sin cohesión social, ni cohesión social sin un sistema de protección de los ciudadanos ante los infortunios del destino, y de acceso universal a los grandes servicios básicos de educación, salud y atención a la dependencia.

La Unión Europea, por su parte, de forma paulatina, ha ido desarrollando una concepción propia de la cohesión social que se ha ido traduciendo en determinadas políticas e iniciativas comunitarias, hasta el punto de que hoy día una parte fundamental de su acción política la constituye su estrategia de cohesión social. Por otra parte, la Unión Europea ha partido del hecho de que las políticas sociales y de cohesión de sus países miembros son una parte fundamental de

${ }^{16}$ Con anterioridad, en el año 2000 el Consejo de Europa aprobó el primer documento de Estrategia para la Cohesión Social. En el punto 8 del documento se refiere a la cohesión social como un ideal que las sociedades deben perseguir continuamente, objetivo que es difícil de definir precisamente por la dificultad de alcanzarlo plenamente, pero que pese a ello hay que hacer lo posible por clarificar. En el apartado siguiente, el 9, se refiere a la cohesión social como aquello que mantiene unidas a las sociedades a través del equilibrio entre las fuerzas centrípetas y centrífugas que operan dentro de ellas. «El conflicto — dice literalmente— es una característica necesaria y permanente de la vida social; la cuestión no es crear un equilibrio de fuerzas permanente sino de construir un equilibrio dinámico. El reto es crear sociedades que puedan manejar el conflicto y el cambio de manera constructiva y creativa». Continúa señalando que lo que importa es identificar los factores que pueden dividir a la sociedad y cita entre ellos las diferencias excesivas entre ricos y pobres, la falta de empleo, la pobreza o la falta de protección social. En 2004, el Consejo de Europa revisó su estrategia de cohesión social, justificando la necesidad de promoverla por los riesgos que la amenazaban, y definiéndola como «la capacidad de una sociedad para asegurar el bienestar de todos sus miembros, minimizando las diferencias y evitando la polarización. Una sociedad cohesionada es una comunidad de individuos libres que se apoyan mutuamente y persiguen estos objetivos comunes por medios democráticos». 
la cohesión social en cada uno de ellos y, por extensión, de la Unión Europea. Por ello, también ha llevado a cabo actuaciones específicas en este ámbito, desarrollando políticas propias y estableciendo mecanismos de cooperación y supervisión de las políticas de los estados miembros. Todo esto se ha construido a través de un largo y complejo proceso que se inicia en el Tratado Constitutivo de la Comunidad Económica Europea de $1957^{17}$, cuyo último hito han sido los Tratados de Lisboa.

En los Tratados de Lisboa se recoge el acervo acumulado en un largo y variado proceso, quedando formulada tanto en el Tratado de la Unión Europea como en el Tratado de Funcionamiento de la Unión Europea.

En el Tratado de la Unión Europea se tratan las cuestiones generales. Se inicia con un preámbulo en el que reconoce inspirarse en la herencia cultural,

17 El TCCEE de 1957 hacía algunas referencias a la política social, centrada sobre todo en la protección de los trabajadores. Se creó ya entonces el Fondo Social Europeo. También se implantó la política agrícola común (PAC), una auténtica política de cohesión aunque no recibiera ese nombre. El Tratado de Maastricht fue el que dio el paso más importante para reforzar la dimensión social de la Unión Europea. Incorporó un apartado nuevo relativo a los objetivos de la Unión Europea y se estableció una definición de la misión de la Unión Europea que reforzaba los aspectos sociales. Para estos fines se previó que la Unión Europea desarrollara una política específica en el ámbito social y otra para el fortalecimiento de la cohesión económica y social. Para reforzar ambos aspectos, el Acta Única Europea añadió sendos protocolos sobre política social y sobre cohesión económica y social. El primero recogía parte del contenido de la Carta Comunitaria de los Derechos Sociales Fundamentales de los Trabajadores, aprobada en 1989. Para reforzar al política de cohesión social se creó un fondo estructural nuevo, el Fondo de Cohesión que reflejaba la idea de reforzar la cohesión dentro de la Unión Europea mediante la creación de infraestructuras que promovieran la integración territorial. Entre el Tratado de Maastricht y el Tratado de Lisboa hubo algunas modificaciones que añadieron más contenido a la política social y de cohesión. Una muy importante se hizo en el Tratado de Ámsterdam, en el que se crea la política comunitaria de empleo. Otra se hizo en el Tratado de Niza, en el que se refuerza la capacidad de la Comisión para apoyar y complementar la capacidad de los Estados miembros en varios aspectos como inmigración y exclusión social, entre otros. Se crea para ello el Comité de Protección Social. A partir de aquí se intensifica la preocupación de la Unión por el problema de la exclusión social e incluso se desarrolla una estrategia específica para ello. Una aportación de orden distinto pero convergente con este proceso fue la aprobación de la Carta de los Derechos Fundamentales, proclamada en Niza en diciembre de 2000, que actualmente tiene el mismo carácter jurídico vinculante que los tratados. También debemos subrayar que la cumbre de Lisboa de Marzo de 2000 constituye uno de los hitos importantes en este proceso. En ella se fijó la estrategia para hacer frente a la globalización de la economía, al crecimiento de las tecnologías de la información y las comunicaciones y a los riesgos y amenazas que se derivaban de ello. En el texto de la Declaración de Lisboa se recoge el ambicioso objetivo que subyace a esa estrategia por el que la economía europea debería «...convertirse en la economía basada en el conocimiento más competitiva...y crecer de manera sostenible con más y mejores empleos y mayor cobesión social... Las personas constituyen el principal activo, por lo que deberían convertirse en el centro de las políticas de la Unión».

N. ${ }^{\circ} 100$, septiembre-diciembre 2017, págs 849-879 
religiosa y humanista de Europa. Se confirma la adhesión a la Carta Social Europea y a la Carta Comunitaria de los Derechos Fundamentales de los Trabajadores. En el artículo 2 se establece que: «La Unión se fundamenta en los valores de respeto de la dignidad humana, libertad, democracia, igualdad, Estado de Derecho y respeto de los derechos bumanos, incluidos los derechos de las personas pertenecientes a minorías. Estos valores son comunes a los Estados miembros en una sociedad caracterizada por el pluralismo, la no discriminación, la tolerancia, la justicia, la solidaridad y la igualdad entre mujeres y hombres». Entre las finalidades que se fijan en el artículo 3 se señala que: «La Unión combatirá la exclusión social y la discriminación y fomentará la justicia y la protección sociales, la igualdad entre mujeres y hombres, la solidaridad entre las generaciones y la protección de los derechos del niño» y que «La Unión fomentará la cobesión económica, social y territorial y la solidaridad entre los Estados miembros».

Por su parte, en el Tratado de Funcionamiento de la Unión Europea se tratan las políticas internas y las cuestiones institucionales. Así, en el artículo 4 del TFUE se fijan las competencias compartidas entre la Unión y los Estados miembros entre las que figuran el empleo, la política social ${ }^{18}$, la cohesión económica social y territorial ${ }^{19}$, y la agricultura y la pesca.

A la vista de la normativa comunitaria se puede decir que en la noción de cohesión social de la Unión Europea subyacen tres aspectos. El primero se refiere a la importancia que se otorga al empleo y a todo lo relacionado con su promoción y con la protección de los trabajadores. Como se repite en muchos documentos de la Unión Europea, el empleo es la mejor política de integración y prevención de la exclusión. El segundo se refiere a la lucha contra la pobreza y la exclusión social, en el contexto del derecho a unas prestaciones suficientes para llevar una vida digna (aquí situaríamos su hilazón más clara con el principio de no regresividad de los derechos sociales). El tercero se refiere a la reducción de las desigualdades sociales, económicas y territoriales. La novedad estriba en el

18 La política social se regula en el título X del TFUE y tiene por objetivo «el fomento del empleo, la mejora de las condiciones de vida y de trabajo, a fin de conseguir su equiparación por la vía del progreso, una protección social adecuada, el diálogo social, el desarrollo de los recursos bumanos para conseguir un nivel de empleo elevado y duradero y la lucha contra las exclusiones».

19 En concreto, la política de cohesión económica, social y territorial se regula en el título XVIII del TFUE. El objetivo de esta política se formula del siguiente modo: «A fin de promover un desarrollo armonioso del conjunto de la Unión, ésta desarrollará y proseguirá su acción encaminada a reforzar su cohesión económica, social y territorial. La Unión se propondrá, en particular, reducir las diferencias entre los niveles de desarrollo de las diversas regiones y el retraso de las regiones menos favorecidas. Entre las regiones afectadas se prestará especial atención a las zonas rurales, a las zonas afectadas por una transición industrial y a las regiones que padecen desventajas naturales o demográficas graves y permanentes como, por ejemplo, las regiones más septentrionales con una escasa densidad de población y las regiones insulares, transfronterizas y de montaña». 
énfasis en la dimensión territorial de la cohesión, además de la dimensión económica. Esto queda claramente reflejado a su vez en los criterios para la asignación de los fondos destinados a equilibrar el desarrollo territorial y en la importancia que se da a las infraestructuras en la cohesión territorial. En suma, «el modelo de cohesión que configura el conjunto de declaraciones y disposiciones que acabamos de describir, refleja y actualiza con creces el acervo heredado de la preocupación europea por la cuestión social... No es un modelo improvisado ni organizado sobre principios aceptados por todos. Ni es un modelo de estabilidad absolutamente garantizada. Es el resultado de un largo proceso de conflictos, negociaciones, cesiones y transacciones que refleja la progresiva maduración institucional de esa experiencia históricamente única que es la construcción de la Unión Europea, que ha hecho posible que por encima de todo siga emergiendo eso a lo que llamamos modelo social europeo» ${ }^{20}$.

Una vez hechas estas referencias al marco europeo de referencia, debemos resaltar la inclusión del concepto de cohesión social en el artículo 3 del Tratado de la Unión Europea y abogamos por la inclusión de un precepto similar en nuestro texto constitucional ${ }^{21}$, que sirviera como fundamento para la inclusión, entre otros, del principio de no regresividad de los derechos sociales ${ }^{22}$.

20 Pérez Yruela, M., op. cit., p. 52.

21 Asunto sobre el que hemos tenido la oportunidad de pronunciarnos en Agudo Zamora, M. (2016), «Reforma constitucional y nuevo paradigma del Estado social. De la ordenación contingente a la organización consciente del Bienestar», Actualidad n. ${ }^{\circ}$ 74, pp. 1-47; y Agudo Zamora, M. (2017), «Cohesión y derechos sociales ante la reforma constitucional», en Reflexiones y propuestas sobre la reforma de la Constitución Española. Álvarez Conde, E. (dir); Álvarez Torres, M. (coord.), Granada, Comares, pp. 115-138.

22 Para algunos autores como PONCE SOLE, J. (2013) El derecho y la (ir)reversibilidad limitada de los derechos sociales de los ciudadanos, Madrid, INAP, pp. 44 y ss.; y MALARET, E (1998) «Servicios Públicos, Funciones Públicas, Garantías de los Derechos de los Ciudadanos: Perennidad de las necesidades, transformación del contexto», Revista de Administración Pública, núm. 145, p. 49 y ss., el objetivo de la cohesión y sostenibilidad social está también presente en nuestra Constitución. En ella, señalan estos autores, se puede encontrar un principio jurídico implícito, que establece como finalidad de la actividad pública el logro de la cohesión social y territorial y la lucha contra la exclusión. Así, el artículo $1 .^{\circ}$, con la referencia al valor igualdad, el artículo $2 .^{\circ}$ referido a la solidaridad entre nacionalidades y regiones, el artículo $9 .^{\circ} 2$, el artículo $14 .^{\circ}$, estableciendo el principio y el derecho a la igualdad, y, entre los derechos del Capítulo III del Título primero, el artículo 40, imponiendo la promoción pública de «condiciones favorables para el progreso social y económico y para una distribución de la renta regional y personal más equitativa», el artículo 45, fijando como finalidad la protección y mejora de la calidad de vida, o, fuera ya de ese ámbito, el mismo artículo 131, refiriéndose al equilibrio y armonía del desarrollo y a la más justa distribución de la renta y de la riqueza, o el artículo 138.1, aludiendo a la solidaridad entre las diversas partes del territorio español, en conexión con el ya citado artículo 2, por ejemplo, diseñan un entramado 


\section{APUNTES DOCTRINALES Y JURISPRUDENCIALES SOBRE EL PRINCIPIO DE NO REGRESIVIDAD DE LOS DERECHOS SOCIALES}

Tal como señala Sala Sánchez, el tema de la reversibilidad de las conquistas sociales no es nuevo en la doctrina y ha estado permanentemente ligado a los avatares y denuncias de crisis del Estado Social. Pero las consecuencias y la permanencia de la grave crisis que estamos sufriendo lo han vuelto a poner en la primera línea de la actualidad ${ }^{23}$.

En las controversias habidas durante las dos últimas décadas del pasado siglo, cabe destacar que algunos autores, siguiendo la doctrina alemana, habían propugnado la irreversibilidad del núcleo esencial de los derechos sociales una vez han sido configurados por el legislador ordinario y en la medida en que por éste se haya realizado la concreción ${ }^{24}$.

En este sentido, la doctrina se ha referido o bien a la irreversibilidad de las conquistas sociales o bien a la teoría garantista de intangibilidad del núcleo esencial de los derechos sociales, al igual que existe en los llamados derechos fundamentales. También se ha abogado por la prohibición de reversibilidad sin razón suficiente de prestaciones sociales acordadas legislativamente bajo la cobertura de derechos sociales reconocidos en la Constitución, al poder incurrir estas medidas restrictivas en arbitrariedad, irrazonabilidad, discriminación o desproporción ${ }^{25}$.

de deberes jurídicos públicos, dirigidos a la finalidad de lograr la vertebración, cohesión, solidaridad y sostenibilidad social.

23 Sala Sánchez P. (2014), «La garantía constitucional de los derechos económicos y sociales y su efectividad en situaciones de crisis económica», en Revista española de control externo, vol. 16, n. ${ }^{\circ} 46$, pp. 11-122.

${ }^{24}$ Teoría que, entre otros, puede consultarse en Parejo Alfonso, L. (1991) Crisis y renovación en el Derecho Público, Madrid, CEC (2000), «El Estado social administrativo: algunas reflexiones sobre la «crisis» de las prestaciones y los servicios públicos», Revista de Administración Pública n. ${ }^{\circ} 153$, septiembre-diciembre, 2000, pp. 217 y ss.; (1983) Estado social y Administración Pública, Madrid, Civitas.

${ }^{25}$ Entre otros, Carro FernándeZ-Valmayor, J. L. (2008), «Derechos fundamentales socioeconómicos y prestaciones esenciales», en Derechos fundamentales y otros estudios en homenaje al prof. Dr. Lorenzo Martín-Retortillo, vol. I, Zaragoza, El Justicia de Aragón; (2012) «Mínimo existencial y jurisprudencia. Hacia la construcción jurisprudencial de un derecho fundamental», en Administración y justicia: un análisis jurisprudencial: liber amicorum Tomás-Ramón Fernández, coord. por Eduardo García de Enterría y Ricardo Alonso García, vol. 2, pp. 3825-3850; y Loperena Rota, D. (2012), «La irreversibilidad de los derechos sociales», en Revista Aranzadi Doctrinal, núm. 9/2012. 
Por su parte, el Tribunal Constitucional no ha fijado una doctrina sobre este asunto, pues en algunas sentencias parece proclive a defender la teoría de la irreversibilidad del contenido legislativamente fijado de los derechos sociales y en otras no. Dentro de las más significativas ${ }^{26}$ podemos encontrar la STC 81/1982, de 21 de diciembre, que otorgó el amparo a los demandantes — hombres, Ayudantes Técnicos Sanitarios-y les reconoció el derecho a no ser discriminados, ni en el salario ni en el resto de su contenido de sus relaciones laborales en relación a turnos de trabajo y abono de horas extras con respecto al personal femenino que realiza idéntico trabajo y posee idéntica cualificación, y matizando que no debe restablecerse la igualdad privando al personal femenino de los beneficios que en el pasado hubiera adquirido, sino otorgando los mismos al personal masculino que realiza idénticos trabajos y actividad profesional, sin perjuicio de que en el futuro el legislador pueda establecer un régimen diferente del actual, siempre que respete la igualdad de los trabajadores, razonando que «no se puede privar al trabajador sin razón suficiente para ello de las conquistas sociales ya conseguidas ${ }^{27}$.

En el mismo sentido, y en relación con la razonabilidad de la solución legislativa, en un caso en que se dilucidaba la incompatibilidad entre la percepción por los funcionarios de las pensiones con cargo a la Seguridad Social y la de haberes activos, el Tribunal Constitucional ha declarado en STC 65/1987, de 21 de mayo, que la existencia de esta doble percepción y su prohibición por la ley no suponía otra cosa que «corregir un tratamiento discriminatorio irregularmente producido, mediante una situación de hecho contraria a la normativa vigente. La situación de los funcionarios al respecto, al no aplicárseles tal prohibición, constituía una excepción a la regla general, sin que por ello pueda estimarse razonable la existencia, en tales circunstancias, de un derecho a confiar en el mantenimiento de esa situación de compatibilidad ${ }^{28}$.

Otra sentencia relevante es la STC 134/1987, de 21 de julio que resuelve una cuestión de inconstitucionalidad interpuesta en relación con los artículos 12.1 y 51 y Disposición adicional quinta, 2, 3 y 4, de la Ley 44/1983, 28 de diciembre, de Presupuestos Generales del Estado para 1984, y en relación con el artículo 12 a) y b) de la Ley de la Comunidad Foral de Navarra 21/1984, de 29 de diciembre, de Presupuestos Generales de Navarra para el ejercicio de 1985, en la que se dispone la no actualización de las pensiones superiores a un deter-

26 Tal como nos recuerda BiURrun Mancisidor, G. (2016), Derechos sociales y jurisprudencia constitucional, pp. 49 y ss., consultada el 16 de junio de 2017 a las 11,15 hs en http://www.iuslabor. org/jornades-i-seminaris/ponencies/

27 Fundamento Jurídico 3. ${ }^{\circ}$

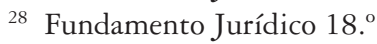


minado límite máximo en el correspondiente ejercicio presupuestario. En esta Sentencia se declaró que no se vulneraba ningún derecho subjetivo a ninguna pensión de cuantía determinada, puesto que la previsión constitucional relativa a la suficiencia de las pensiones no ha de analizarse respecto de cada concreta e individual pensión, sino en relación con el sistema de pensiones en su conjunto, sin que pueda prescindirse de las concretas circunstancias económicas y sociales de cada momento, sin olvidar que el Estado ha de administrar medios económicos limitados y atender a un gran número de necesidades sociales ${ }^{29}$.

También de relevancia en este terreno es la STC 37/1994, de 10 de febrero, que resuelve varias cuestiones de inconstitucionalidad planteadas en relación con el artículo 129.1 de la Ley General de la Seguridad Social en la redacción dada al mismo por el Real Decreto-ley 5/1992, de 21 de julio, y por la Ley 28/1992, de 24 de noviembre, la primera, y respecto del artículo 6.1, párrafos primero y último, del Real Decreto-ley 5/1992, de 21 de julio; de la Ley 28/1992, de 24 de noviembre. En esta sentencia se abordaba la obligación impuesta a los empresarios de satisfacer la prestación económica de incapacidad laboral transitoria en determinado período de la baja de la persona trabajadora y a la imposibilidad de retornar a la percepción del subsidio de desempleo una vez perdido éste por percepción de rentas superiores a los máximos legalmente establecidos aunque posteriormente hubiera descendido el nivel de rentas por debajo del umbral establecido para el nivel asistencial. Pues bien, el Tribunal Constitucional recuerda que el sistema de Seguridad Social consagrado en el artículo $41 \mathrm{CE}$ concibe a éste como una función del Estado, rompiendo en buena parte la correspondencia prestación-cotización propia del seguro privado, que los poderes públicos tienen la obligación de mantener ese sistema y que su «preservación se juzga indispensable para asegurar los principios constitucionales, estableciendo (...) un núcleo o reducto indisponible por el legislador (...) de tal suerte que ha de ser preservado en términos reconocibles para la imagen que de la misma tiene la conciencia social en cada tiempo y lugar», pero recordando también que dispone «el legislador de libertad para modular la acción protectora del sistema en atención a circunstancias económicas y sociales que son imperativas para la propia viabilidad y eficacia de aquél» ${ }^{30}$.

Por lo tanto, tal como se desprende de estas sentencias, podemos señalar que nuestro Tribunal Constitucional no ha mantenido al respecto una postura firme puesto que si bien ha sostenido que «no se puede privar al trabajador sin razón

\footnotetext{
29 Fundamento Jurídico 5. ${ }^{\circ}$

30 Fundamento Jurídico $3 .^{\circ}$, que también puede encontrarse en la STC 128/2009, Fundamento Jurídico $4 .^{\circ}$
} 
suficiente para ello de las conquistas sociales ya conseguidas» también ha declarado que el legislador, apreciando la importancia relativa de las situaciones de necesidad a satisfacer, regule, en atención al contexto general en que se produzcan, y en conexión con las circunstancias económicas, las disponibilidades del momento y las necesidades de los grupos sociales, el nivel y condiciones de las prestaciones a efectuar, o las modifique para adaptarlas a las necesidades del momento.

En este sentido, la doctrina entiende que de lo declarado por el Tribunal Constitucional se concluye que las regresiones pueden justificarse solamente por razones de índole social o, tal como señala Escobar Roca, «las regresiones sobre derechos fundamentales sociales de prestación resultan constitucionales siempre que se justifiquen en algo más que en la apelación a la Economía o al principio democrático» ${ }^{31}$. En un sentido parecido, Ojeda Marín entiende que «tomando como referencia el vigente texto constitucional, podemos considerar lícito el recorte de algunos derechos sociales enunciados en la Constitución, siempre y cuando se mantengan a salvo dos condiciones: la observancia de los principios y valores constitucionales y, en segundo lugar, el respeto del contenido esencial cuando así proceda» ${ }^{32}$.

Por eso resulta interesante preguntarse si los derechos sociales son de desarrollo progresivo o si tienen un núcleo esencial. La respuesta, siguiendo a Arango, parece ser disyuntiva porque ambos extremos en principio se excluyen. De aceptarse que los derechos sociales dependen para su realización de circunstancias normativas y fácticas, son concebibles casos de anulación absoluta de los mismos en circunstancias extremas (este autor señala el ejemplo de la existencia de un tsunami). Esto contraría, no obstante, la doctrina del contenido esencial, la cual prohíbe el desconocimiento de mínimos materiales. A la inversa, señala este autor, si se acoge la doctrina del contenido esencial y se asegura así un contenido deontológico a los derechos, entonces se estaría incurriendo en una especie de «intuicionismo moral», ajeno a la progresividad. Nos encontraríamos, concluye, «ante la teoría interna de los derechos, según la cual su contenido se encuentra

31 Escobar Roca, G. (2012), «Los derechos fundamentales sociales de prestación», en Escobar Roca, G. (dir.), Derechos sociales y tutela antidiscriminatoria, Navarra, Thomson Reuters Aranzadi, p. 632 y ss. Doctrina que sigue la ya señalada de Parejo (2000), op. cit., p. 226 y ss., quien entiende que las regresiones resultan legítimas, pues así lo impone el pluralismo político y por tanto el principio democrático, si cumplen dos requisitos: existencia de soluciones prestacionales a situaciones de necesidad social en términos de garantía constitucional directa de los mismos indisponible por el legislador ordinario que actúa como límite infranqueable para el legislador; y fundamento suficiente.

32 Ojeda Marin, A. (1996), Estado social y crisis económica, Madrid, Ed. Complutense, p. 105. 
ab initio prefigurado, lo que permite su defensa como reglas, siendo las excepciones los casos de mera apariencia de derechos» ${ }^{33}$. Ahora bien, si se postula la doctrina del carácter progresivo, gradual y contextual de los derechos, la llamada teoría externa de los derechos, según la cual su contenido, en casos de colisión con otros principios de igual jerarquía, solo puede determinarse por vía de una ponderación que atienda las circunstancias fácticas y normativas del caso, entonces podría defenderse la prohibición de la regresividad de los derechos sociales como una veda a aquellas medidas que hagan renacer obstáculos de carácter económico o social que limitan de hecho la libertad e igualdad de las personas e impiden el desarrollo de la personalidad humana y la efectiva participación de todos en la vida cultural, económica, social y política. O dicho de otro modo, como un impedimento para aquellas medidas de carácter legislativo que fueran en detrimento de los principios de cohesión y solidaridad social.

Así lo entiende Courtis, defensor de una teoría evolucionista de los derechos sociales, cuando señala que «la prohibición de regresividad opera como cláusula de control jurídico del cumplimiento, por parte de los poderes públicos, del mandato del Estado social» ${ }^{34}$, puesto que el contenido de las necesidades básicas, las posibilidades de desarrollo de las personas y las áreas de participación se amplían con el progreso social, científico y material de nuestras sociedades, por lo que el umbral de protección (y por ende las posiciones consolidadas no susceptibles de derogación o supresión, añade este autor) también tienden a ir ampliándose progresivamente.

\section{LÍMITES A LA REGRESIVIDAD DE LOS DERECHOS SOCIALES}

Las normas jurídicas persiguen unos determinados objetivos y buscan la obtención de ciertas finalidades dentro del conjunto social al que se dirigen y dentro, también, de un sistema de valores y principios democráticamente establecido, en la Constitución, en primer lugar, y, secundariamente, en el conjunto del Ordenamiento Jurídico que el pueblo establece a través de sus legítimos representantes. Sistema axiológico que ha de tenerse en cuenta a la hora de la aplicación de las normas. Por ello, para una corriente crítica y evolutiva del

33 Arango, R. (2006), «Prohibición de retroceso en Colombia», en Christian Courtis (Comp.). Ni un paso atrás. La probibición de regresividad en materia de derechos sociales», Buenos Aires, Cedal/Cels, pp. 153-171.

34 Courtis, C. (2006), «La prohibición de regresividad en materia de derechos sociales: apuntes introductorios», en Christian Courtis (Comp.) Ni un paso atrás. La probibición de regresividad en materia de derechos sociales, Buenos Aires, Cedal/Cels, p. 48 y ss. 
pensamiento jurídico, en la que nos alineamos, los elementos de interpretación sociológica y teleológica han de ser criterios extensamente empleados, por parte de los jueces, a la hora de la interpretación y la aplicación de las normas. Por lo tanto, para las denominadas corrientes críticas, a diferencia de otras corrientes ${ }^{35}$, se recurre también a los datos proporcionados por otras ciencias sociales a la hora de la interpretación y de la elaboración de criterios para el desarrollo, modificación y defensa de las reglas jurídicas existentes.

Desarrollo y defensa que se hacen precisos para garantizar los objetivos, ya señalados, que conforman la esencia y existencia del Estado social. El carácter normativo de la Constitución y la particular naturaleza de los principios/derechos que, en la misma, lo hacen realidad ha llevado al Tribunal Constitucional ${ }^{36}$ a decir que su carácter vinculante pasa:

1. Por reconocer que tales principios no son normas jurídicas sin contenido y que enuncian auténticas proposiciones vinculantes que, en cualquier caso, deben de informar la legislación positiva y la práctica judicial, de manera que obligan a los poderes públicos - legislativo, ejecutivo y, en particular, al judicial por la función de aplicación del Derecho que desarrolla- a tenerlos presentes en la interpretación tanto de las restantes normas constitucionales como de las leyes.

2. ${ }^{\circ}$ Por afirmar que estos principios, en los términos que están protegidos en el artículo 53.3 CE, tienen limitada su efectividad, siendo principios que deben de orientar la actuación de los poderes públicos pero que no generan por sí mismos derechos judicialmente actuables, de suerte que en ocasiones habrá que esperar a que el legislador realice la regulación correspondiente, si bien eso no

35 Básicamente, tal como señala DíAz RocA, R. (1997), Teoría General del Derecho. Madrid, Tecnos, podemos extraer tres doctrinas de acercamiento a la interpretación de las normas jurídicas. a) la exégesis que consiste en interpretar la norma desde la norma misma, sin recurrir a otras y, por supuesto, sin abandonar el campo jurídico. En esta doctrina se utiliza exclusivamente la interpretación literal o gramatical de la norma; b) la dogmática que entiende que la interpretación literal es claramente insuficiente, por lo que se plantea la necesidad de recurrir a vías alternativas. Partiendo de la consideración de que las normas están imbuidas de un sentido racional, esta corriente utiliza, en primer lugar, la interpretación lógica de las normas, deduciendo su auténtico sentido de las conexiones lógicas que resultan de los conceptos y de las proposiciones que forman las normas. Posteriormente, y partiendo de la idea de que toda norma es parte de un conjunto organizado lógicamente, se emplea la interpretación sistemática, que abarca todas las normas del Ordenamiento; c) la crítica, que parte de la idea de que las normas jurídicas persiguen unos determinados objetivos y buscan la obtención de ciertas finalidades dentro del conjunto social al que se dirigen y dentro, también, de un sistema de valores y principios dado, que ha de tenerse en cuenta a la hora de la aplicación de las normas.

36 Entre otras, la STC 14/92, de 10 de febrero. 
quita para que los mismos, como contenidos constitucionales mínimos que son, puedan invocarse directamente ante los tribunales sin que aquélla se haya producido.

Esta misma corriente de interpretación jurídica de los contenidos y desarrollo del Estado social nos conmina a reflexionar, pues, sobre los límites a la regresividad de los derechos sociales en nuestro ordenamiento jurídico.

Y para ello, establecemos un modelo de límites que derivan de tres aspectos, al que podría añadirse un cuarto derivado de la utilización de la figura normativa del decreto-ley a la hora de aprobar estas medidas regresivas, pero que no analizaremos al tratarse de la aplicación de una prohibición que con carácter general se impone a cualquier decreto-ley que afectara a cualquiera de «los derechos, deberes y libertades de los ciudadanos regulados en el Título I» (art. 86.1 CE).

a) Límites derivados del ordenamiento internacional.

b) Límites derivados de la dignidad como contenido esencial de los derechos sociales.

c) Límites derivados de la prohibición de la arbitrariedad: la necesidad de una suficiente motivación.

\section{a) Límites derivados del ordenamiento internacional}

Debemos comenzar afirmando que la regresividad injustificada de los derechos sociales es contraria al Derecho internacional, y, por aplicación de los artículos 10.2 y de los contenidos en el capítulo tercero del Título III de nuestra Constitución, también a nuestro ordenamiento jurídico.

En el Pacto Internacional de los Derechos Económicos, Sociales y Culturales, se impone a los Estados la obligación de progresividad de los derechos sociales: «Cada uno de los Estados partes en el presente Pacto se compromete a adoptar medidas [...] para lograr progresivamente [...] la plena efectividad de los derechos aquí reconocidos» (art. 2.1) ${ }^{37}$.

El Comité de Derechos Económicos, Sociales y Culturales, organismo encargado de supervisar este Pacto, ha establecido que «todas las medidas de carácter

37 En la misma dirección, podemos citar también el art. 11.1, que señala que «los Estados Partes del presente Pacto reconocen el derecho de toda persona a un nivel de vida adecuado para sí y su familia, incluso alimentación, vestido y vivienda adecuados, y a una mejora continúa de las condicionas de existencia. Los Estados Partes tomarán medidas apropiadas para asegurar la efectividad de este derecho, reconociendo a este efecto la importancia esencial de la cooperación internacional fundada en el libre consentimiento». 
deliberadamente regresivo requerirán la consideración más cuidadosa y deberán justificarse plenamente por referencia a la totalidad de los derechos previstos en el Pacto y en el contexto del aprovechamiento pleno del máximo de los recursos de que se disponga» ${ }^{38}$, así como que existe una «obligación de proceder lo más expedita y eficazmente posible con miras a lograr ese objetivo». Para este Comité, el Estado debe justificar la plena utilización del máximo de los recursos disponibles antes de adoptar cualquier medida regresiva, y analizar el impacto en los derechos humanos previamente a la adopción de la misma, así como respetar el contenido mínimo esencial de los derechos, y la proporcionalidad, temporalidad y carácter no discriminatorio de la medida. Asimismo, el Estado debe garantizar la participación en el diseño de las medidas de las personas afectadas por las medidas y las organizaciones que las representan.

Por su parte, el Consejo de Derechos Humanos, tal como nos recuerda el Informe de Amnistía Internacional, Greenpeace y Oxfam Intermon ${ }^{39}$, destaca que «las crisis económicas y financieras mundiales no disminuyen la responsabilidad de las autoridades estatales en la realización de los derechos humanos» ${ }^{40}$. Además, «el ejercicio de los derechos humanos, incluido el derecho a la salud, no puede subordinarse a la aplicación de las políticas de ajuste estructural» ${ }^{41}$.

En el Consejo de Europa, el Comité Europeo de Derechos Sociales ha derivado el principio de no regresividad del artículo 12.2 y 3 de la Carta Social Europea $^{42}$. Por su parte, el Comisario Europeo de derechos humanos ${ }^{43}$, denunciando el impacto de las medidas de austeridad sobre los derechos humanos, y en especial sobre los sociales, ha recordado la importancia del principio de no regresividad como garantía necesaria de estos. Especialmente relevante, siguiendo esta misma tónica, resulta la Observación General n. ${ }^{\circ} 14$ del Comité de Derechos Económicos, Sociales y Culturales al señalar que «al igual que en el caso de los demás derechos enunciados en el Pacto, existe una fuerte presunción

38 Observación General 3. ${ }^{a}$, de 1990.

39 Informe de Amnistía Internacional, Greenpeace y Oxfam Intermón (2015) Una reforma para blindar los derechos bumanos.

40 Resolución S-10/1, de 2009.

41 Resolución 11/5, de 2009.

42 «Artículo 12. Derecho a la seguridad social. Para garantizar el ejercicio efectivo del derecho a la seguridad social, las Partes Contratantes se comprometen: 1. A establecer o mantener un régimen de seguridad social. 2. ${ }^{\circ}$ A mantener el régimen de seguridad social en un nivel satisfactorio, equivalente, por lo menos, al exigido para la ratificación del Convenio internacional del trabajo (número 102) sobre normas mínimas de seguridad social. 3..$^{\circ}$ A esforzarse por elevar progresivamente el nivel del régimen de seguridad social. 4 . $^{\circ} \ldots$...

43 CommDH (2013)18, Informe de Nils Muižnieks, Comisario para los Derechos Humanos del Consejo de Europa, párrafos 41 y ss. 
de que no son permisibles las medidas regresivas adoptadas en relación con el derecho a la salud. Si se adoptan cualesquiera medidas deliberadamente regresivas, corresponde al Estado Parte demostrar que se han aplicado tras el examen más exhaustivo de todas las alternativas posibles y que esas medidas están debidamente justificadas por referencia a la totalidad de los derechos enunciados en el Pacto en relación con la plena utilización de los recursos máximos disponibles del Estado Parte» ${ }^{44}$.

En conclusión, distintos organismos de Naciones Unidas han denunciado el riesgo de las regresiones en los niveles de protección de los derechos sociales. Entre ellos el Comité de Derechos Económicos, Sociales y Culturales, que, como hemos señalado, impele a España a garantizar que todas las medidas de austeridad implementadas mantengan el nivel alcanzado de protección de los derechos económicos, sociales y culturales, y sean en todos casos temporales, proporcionales y no perjudiciales para estos derechos. Además, todas las medidas de austeridad adoptadas han de identificar el contenido mínimo esencial de todos los derechos y proteger este contenido esencial en cualquier circunstancia. También se ha de aumentar la eficacia de los esfuerzos estatales para la protección de los derechos económicos, sociales y culturales. Razonamientos similares aparecen en los Informes sobre España de 2013, tanto del Comité de Derechos Económicos, Sociales y Culturales como del Comisario Europeo de derechos humanos, que hemos reseñado.

En relación a nuestro ordenamiento constitucional y los compromisos internacionales asumidos puede considerarse, pues, que España está vinculada a los principios de progresividad y no regresividad, tal y como han sido establecidos en el Derecho internacional, con apoyo en los artículos 10.2 y 96.1 CE. Incluso relacionando los compromisos internacionales del Estado español en relación al contenido de los artículos 9.2 y 9.3, podrían encontrarse argumentos a favor de esta tesis, máxime si se imbrica con el modelo de Estado social que nuestra Constitución establece en su primer artículo ${ }^{45}$.

44 E/C.12/2000/4, CESCR Observación General 14. (2000), sobre El derecho al disfrute del más alto nivel posible de salud, párrafo 32.

45 En cuanto al Derecho comparado, algunos Tribunales Constitucionales o Supremos han deducido este principio de sus Constituciones. Es el caso de Alemania, Argentina, Canadá, Francia, Portugal o Italia, ver Ponce Sole, J. (2013), op. cit. p. 54 y ss. Para la situación en Alemania ha de citarse Vidal Prado C. (2013), «Los derechos sociales y sus garantías: los casos de Italia y Alemania», en Narciso Martínez Morán, Ana María Marcos del Cano, Rafael Junquera de Estéfani (coords.) Derechos humanos: problemas actuales: estudios en homenaje al profesor Benito de Castro Cid, vol. 2, Madrid, Universitas, p. 1115 y ss. 


\section{b) Limites derivados de la dignidad como contenido esencial de los derechos sociales}

La existencia de un núcleo esencial en los derechos de naturaleza social ha sido un tema controvertido cuando se trata de derechos incluidos en el capítulo tercero del Título I de nuestra Constitución ${ }^{46}$. Esto se debe a que el contenido esencial del derecho supone un obstáculo insalvable frente a cualquier intento de los poderes públicos de limitar un derecho fundamental, dado que las restricciones de los derechos fundamentales que afecten a su contenido esencial son inconstitucionales ${ }^{47}$.

La delimitación de lo qué supone el contenido esencial fue realizada por el Tribunal Constitucional en una de sus primeras sentencias ${ }^{48}$, identificando dos caminos que permitan establecer el mismo:

a) El primero de ellos acude a la naturaleza jurídica del derecho, o al modo de ser concebido según las ideas generalizadas y convicciones generalmente admitidas entre los juristas, los jueces y, en general, los especialistas en Derecho. Dice el Tribunal Constitucional en este sentido que «constituyen el contenido esencial de un derecho subjetivo aquellas facultades o posibilidades de actuación necesarias para que el derecho sea reconocible como pertinente al tipo descrito y sin las cuales deja de pertenecer a ese tipo y tiene que pasar a quedar comprendido en otro, desnaturalizándose, por decirlo así. Todo ello referido al momento histórico de que en cada momento se trata y a las condiciones inherentes en las sociedades democráticas, cuando se trate de derechos constitucionales».

b) El segundo de los caminos trata de buscar lo que se ha venido en llamar los intereses jurídicamente protegidos como núcleo y médula de los derechos subjetivos. Se puede entonces hablar de una esencialidad del contenido del derecho para hacer referencia a aquella parte de su contenido que es absolutamente

46 No, desde luego, si se trata de derechos reconocidos constitucionalmente como derechos fundamentales (derecho a la educación, libertad sindical y derecho de huelga de los trabajadores,

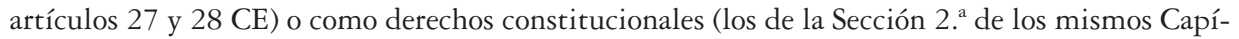
tulos y Título ), puesto que el reconocimiento de un núcleo esencial, salvaguardado incluso frente al legislador, para estos derechos y libertades está expresamente establecido por el artículo 53.1 de la Constitución, como ya se advirtió anteriormente, nos recuerda Sala SAnchez, P., op. cit. p. 77 y ss.

47 Aunque el artículo 53.1 CE solo menciona el contenido esencial como límite a la acción del legislador, lo cierto es que tiene virtualidad frente a cualquier poder público. Si todos ellos están sujetos a los derechos fundamentales, lo están igualmente a lo que no es sino un componente del mismo: su contenido esencial, nos recuerda NARANJo DE LA CrUZ, R. (2016), «Capítulo XVII. El sistema de derechos constitucionales y su garantía», en AGUdo y otros Manual de Derecho Constitucional, Madrid, Tecnos, p. 438.

48 STC 11/1981, fundamento jurídico $8 .^{\circ}$ 
necesaria para que los intereses jurídicamente protegibles, que dan vida al derecho, resulten real, concreta y efectivamente protegidos. De este modo, se rebasa o se desconoce el contenido esencial cuando el derecho queda sometido a limitaciones que lo hacen impracticable, lo dificultan más allá de lo razonable o lo despojan de la necesaria protección.

La doctrina ${ }^{49}$ ha señalado que el núcleo mínimo de los derechos sociales encuentra considerable parecido con el que es indisponible, incluso para la ley, cuando se trata de los «clásicos» derechos fundamentales. En esta línea de pensamiento, no puede caber duda de que el núcleo esencial de un derecho social ha de estar ligado necesariamente a la dignidad de la persona. Y esto es así, porque se encuentra en la esencia misma y en el más extendido acervo del Constitucionalismo: el respeto de los derechos constituye el fundamento del orden político y de la paz social en los Estados de Derecho, estableciéndose un estrecho nexo de interdependencia genético y funcional entre el Estado de Derecho y los derechos, y por ende entre el Estado social y los derechos sociales; ya que igual que el Estado de Derecho exige e implica para serlo garantizar los derechos en general, mientras que éstos exigen e implican para su realización al Estado de Derecho, igualmente el Estado social y el reconocimiento, eficacia y protección de los derechos sociales están íntimamente unidos.

La mayor o menor amplitud del reconocimiento constitucional de los derechos, así como el nivel de protección o garantías de los que disfruten, suponen un parámetro suficientemente indicativo de la legitimidad democrática del orden político, existiendo una profunda relación entre el papel asignado a los derechos y libertades y el sistema de organización y ejercicio de las funciones estatales. En la normativa constitucional de los países democráticos, los derechos gozan, pues, de un doble carácter, presentándose como un conjunto de valores objetivos básicos y como el marco de protección de las situaciones jurídicas subjetivas. Desempeñan, por tanto, una doble función: en el plano subjetivo, actúan como garantías de la libertad individual y de los aspectos sociales y colectivos de la subjetividad, mientras que en el objetivo, asumen un componente institucional, funcionando como medio para el logro de los fines y valores constitucionales.

Partiendo del rango de fundamento del orden político que ostentan los derechos, el Tribunal Constitucional ha formulado la doctrina de la doble naturaleza, subjetiva y objetiva, de los derechos fundamentales. Así el Tribunal ha declarado que «en primer lugar, los derechos fundamentales son derechos subjetivos, derechos de los individuos no solo en cuantos derechos de los ciudadanos en sentido

49 Vid. Ponce Sole, J., op. cit, pp. 64 y ss.; Carro Fernández-Valmayor, J. L. op. cit. p. 377 y ss. y Sala Sanchez, P., op. cit. p. 78 y ss. 
estricto, sino en cuanto garantizan un «status» jurídico o la libertad en un ámbito de existencia. Pero al propio tiempo, son elementos esenciales de un ordenamiento objetivo de la comunidad nacional, en cuanto ésta se configura como marco de una convivencia humana justa y pacífica, plasmada históricamente en el Estado de Derecho y, más tarde en el Estado social de Derecho o el Estado social y democrático de Derecho, según la fórmula de nuestra Constitución» ${ }^{50}$.

El primer artículo de nuestra Constitución, tras definir la forma de Estado, proclama como valores superiores del ordenamiento la libertad, la justicia, la igualdad y el pluralismo político. Este precepto se conecta estrechamente con el que inaugura el Título I, que, entre los fundamentos del orden político y de la paz social, incluye la dignidad de la persona humana; pues es evidente que dichos valores superiores del ordenamiento necesitan como presupuesto básico para su plena existencia el íntegro desarrollo ético de los miembros de la sociedad que por ellos se rige. Por lo tanto el reconocimiento de derechos no es sino la manifestada obligación de la primacía del valor constitucional último: la dignidad de la persona humana, al que está íntimamente unido el libre desarrollo de la personalidad ${ }^{51}$.

$\mathrm{Y}$ en este momento, volvemos atraer a colación la doctrina del Comité de Derechos Económicos, Sociales y Culturales, que señala la obligación de mantener el nivel alcanzado de protección de los derechos económicos, sociales y culturales, y que las regresiones en su contenido han de ser en todos casos temporales, proporcionales y no perjudiciales para estos derechos. Además, todas las medidas de austeridad adoptadas han de identificar el contenido mínimo esencial de todos los derechos y proteger el mismo en cualquier circunstancia. Contenido que como hemos señalado implica el reconocimiento y protección de aquellas facultades o posibilidades de actuación necesarias para que el derecho sea reconocible como pertinente al tipo descrito y sin las cuales deja de pertenecer a ese. Así pues, puede concluirse que los derechos sociales encierran un contenido esencial que no puede ser restringido o degradado, al igual que ocurre con el resto de los derechos.

Por lo tanto, un límite infranqueable de las medidas que supongan regresividad de los derechos sociales sería el respeto del contenido esencial de los derechos sociales como manifestación de la dignidad humana.

50 STC 25/81, de 14 de julio.

51 En esta línea, PECEs Barba cree que «la dignidad de la persona es el fundamento y la razón de la necesidad de estos valores superiores, es la raíz última de todo» y que éstos son «los caminos para hacer real y efectiva la dignidad humana». PECEs BARBA, G. (1984), Los valores superiores. Madrid, Tecnos, p. 85 y ss. Y así también lo ha entendido el Tribunal Constitucional (STC 53/1985, F.J. 8. ${ }^{\circ}$; STC 120/1990, F.J. 4. '; STC 113/1989, F.J. 3. .; STC 181/2000, F.J. 9. '; o STC 19/2012, F.J. 4. ${ }^{\circ}$, entre otras). 
c) Límites derivados de la probibición de la arbitrariedad: la necesidad de una suficiente motivación

Como es bien conocido, la Constitución prohíbe la actuación arbitraria de cualquier poder público — legislativo, ejecutivo y judicial-como equivalente a cualquier conducta pública no adecuada a la legalidad, o que pretende un fin constitucionalmente ilícito, o, finalmente, que aparezca como desproporcionada al fin que pretenda, aunque éste sea lícito ${ }^{52}$, siendo una de las manifestaciones del principio de seguridad jurídica que da sentido a nuestro Estado de derecho ${ }^{53}$. Se puede entender, con la STC 147/1986, de 25 de noviembre, que la seguridad jurídica en el ámbito social supone la confianza que los ciudadanos pueden tener en la observancia y respeto de las situaciones derivadas de la aplicación de normas válidas y vigentes de contenido social.

Reconoce el Tribunal Constitucional que el principio de seguridad jurídica es probablemente el principio de mayor alcance de los descritos en el artículo 9.3 CE, pues es suma de certeza y legalidad, jerarquía y publicidad normativa, irretroactividad de lo no favorable e interdicción de la arbitrariedad, aunque el entendimiento de este principio no puede ser tan absoluto que genere el anquilosamiento del ordenamiento jurídico porque éste siempre ha de responder a la realidad social de cada momento.

El «carácter social y democrático del Estado de Derecho que nuestra Constitución erige» ${ }^{54}$ y la obligación que al Estado impone el artículo 9.2 de promover las condiciones para que la igualdad de los individuos y de los grupos sean reales y efectivas implica que a la hora de adoptar una medida regresiva de índole social la motivación haya de ser suficiente. En este sentido no puede considerarse motivación suficiente, tal como señala Sala, «la apelación genérica a situaciones de crisis o incluso a los principios de sostenibilidad económica y estabilidad presupuestaria también recogidos en el Texto Fundamental. Restricciones lineales de derechos sociales ya configurados como derechos subjetivos, paralelas a otras restricciones presupuestarias en el gasto, no significarían otra cosa que desconocer la normatividad de la Constitución o degradar los derechos, mandatos o habilitaciones constitucionales a la condición de meras declaraciones programáticas. La sola existencia de un mandato constitucional dirigido a los poderes públicos para el aseguramiento y logro de las finalidades expresamente

52 STC 66/1985, de 23 de mayo.

53 Sobre este asunto, entre otros, FERnandez Rodriguez, T. R. (1998). De la arbitrariedad del legislador, Madrid, Civitas.

54 STC 81/1982, de 21 de diciembre. 
recogidas en los preceptos contenidos en el Capítulo III del Título I de la Constitución, significa claramente que la restricción de un derecho configurado a la luz de tales mandatos exigiría que el legislador razonara con la precisión suficiente que, previamente a la restricción del derecho social, ha restringido gastos no supeditados a «específicos» mandatos constitucionales.» 55

En este mismo sentido citamos el Voto particular ${ }^{56}$ de Valdés Dal-Ré a la STC 139/2016, cuando expresa la necesidad de que se produzca una motivación reforzada en sustento de la asunción de la medida en liza. Y ello, por tratarse de una medida regresiva a la que es aplicable la doctrina del Comité del Pacto internacional de derechos económicos sociales y culturales, que establece que si se adoptan cualesquiera medidas deliberadamente regresivas, corresponde al Estado Parte demostrar que se han aplicado tras el examen más exhaustivo de todas las alternativas posibles y que esas medidas están debidamente justificadas por referencia a la totalidad de los derechos enunciados en el Pacto en relación con la plena utilización de los recursos máximos disponibles del Estado Parte.

Igualmente también es preciso que la medida regresiva sea proporcionada; ha de constituir un medio coherente para alcanzar el fin que se pretenda, entendiéndose por coherente el que menos merme el derecho social afectado y que el beneficio que proceda de la restricción supere los perjuicios que se deriven de ella. Se ha de exigir también que exista ponderación entre la medida y sus efectos y el derecho social concernido.

Por lo tanto, nos encontramos con tres criterios que han de tenerse en consideración a la hora de justificar con motivación suficiente una medida normativa regresiva: que se pretenda un fin constitucionalmente legítimo, que la medida sea proporcionada y que se razone con precisión la existencia de restricciones previas en otros gastos no supeditados a la eficacia de mandatos constitucionales específicos de índole social.

Igualmente, y solo a título de referencia, podemos señalar que podemos encontrar otro tipo de limitaciones a las medidas que supongan regresividad de los derechos sociales en función de otros principios constitucionales, tales como el de seguridad jurídica, ya nombrado, el de confianza legítima, el de no discriminación o el de la irretroactividad de disposiciones restrictivas de derechos individuales. También estos principios, si bien con menor aplicación en materia de jurisprudencia sobre los derechos sociales, tienen indudable repercusión a la

55 Op. cit, p. 74.

56 Apartado III.3 del Voto Particular que formula el magistrado Fernando Valdés Dal-Ré a la Sentencia 139/2016, de 21 de julio, y al que se adhiere la Magistrada doña Adela Asua Batarrita. 
hora de valorar la viabilidad constitucional de las regresiones que sobre los mismos puedan acordarse legislativamente ${ }^{57}$.

\section{A MODO DE CONCLUSIONES: REFORMA CONSTITUCIONAL Y NO REGRESIVIDAD DE LOS DERECHOS SOCIALES}

1. El Derecho, como el Estado, es, utilizando la expresión clásica de Hobbes, resultado de la «técnica del hombre», es puro artificio, es un instrumento que está permanentemente a disposición de los titulares del poder para incidir en la realidad, para modificarla, para transformarla. De ahí que en las diferentes ramas del ordenamiento jurídico no existan cláusulas de reforma. El ordenamiento jurídico del Estado se va integrando por el conjunto de normas que los poderes públicos, elegidos democráticamente por la sociedad, estiman que son necesarias para hacer frente a los problemas que se plantean en cada momento. Por esa razón las normas se crean, entran en vigor, se aplican y cuando los problemas cambian o las soluciones dadas en las mismas se muestran insuficientes ante la demanda social, las normas se modifican o derogan. Ese es el juego del Derecho. Y por eso las normas no incluyen dentro de su contenido ninguna cláusula específica de reforma.

En el ámbito del Derecho Constitucional, por el contrario, la cuestión es bien distinta. La cláusula de reforma constitucional, o sea las previsiones contenidas en el propio texto constitucional acerca de los mecanismos a través de los cuales han de introducirse cambios, modificaciones o adiciones en su texto, es decir, el procedimiento a través del cual la Constitución prevé su propia reforma, es un componente necesario, absolutamente imprescindible de la Constitución, que deriva, entre otras razones, de la naturaleza básicamente política de la norma constitucional. La Constitución es la única norma en el mundo del Derecho a la que se le plantea como tarea la realización de un objetivo titánico: armonizar la existencia de un Estado que ostenta, siguiendo la clásica formulación de Max Weber, «el monopolio del ejercicio de la fuerza» y que es el creador de todo el Derecho con la necesidad de las sociedades democráticas de juridificar el ámbito de las relaciones sociales, y de someter, en consecuencia, el poder del Estado al control de formas jurídicas, así como de garantizar un contenido esencial de los derechos y libertades, incluidos los de índole social, que hagan real y efectiva la dignidad humana bajo los valores colectivos de libertad, igualdad y solidaridad.

2. La Constitución es, pues, la síntesis de las relaciones entre Estado y Derecho; es, como recuerda Burdeau «el punto de intersección entre la política y el derecho». Desde esta óptica, podemos decir, pues, que la reforma constitucional

57 Pueden estudiarse con detalle en Ponce, op. cit. p. 79 y ss. 
no es la respuesta a una situación patológica, sino un hecho fisiológico. La Constitución se reforma porque la reformabilidad es un componente necesario de las Constituciones.

Y siguiendo esta necesidad se justificó la reforma constitucional de septiembre de 2011 del artículo 135 CE. Aun siendo entendible por el contexto socioeconómico e internacional de aquel momento, se puede afirmar, varios años después, que aquella fue una ocasión perdida para relacionar Política y Constitución con una visión más amplia, pues se enfatizó en la necesidad de garantizar el principio de estabilidad presupuestaria, vinculando a todas las Administraciones Públicas en su consecución, de reforzar el compromiso de España con la Unión Europea y, al mismo tiempo, de garantizar la sostenibilidad económica y social de nuestro país; pero, en cambio, no se incluyeron referencias expresas al correlato derivado del objetivo comunitario de fomentar la cohesión económica, social y territorial en Europa, así como la solidaridad. En otras palabras, se perdió la oportunidad de incluir referencias expresas al modelo social europeo, de «blindar» a nivel constitucional el Estado social ligándolo al principio, no solo de estabilidad presupuestaria, sino también al que supone hacer real los fines y objetivos propios de este modelo de Estado, los principios de solidaridad y cohesión social, pues como se ha señalado previamente, la cohesión social es un concepto político que es esencial para ligar los tres valores centrales del modelo político europeo: los derechos y libertades, incluidos los de naturaleza socioeconómica, la democracia y el imperio de la ley.

3. El artículo 135.4 CE señala que cuando se alcanzan los límites de déficit o deuda no podrá existir «ninguna regla o medida social que aumente el gasto mientras no se arbitren otras que reduzcan otros gastos públicos o aumenten los ingresos en igual o mayor medida», salvo en el «caso de catástrofes naturales, recesión económica o situaciones de emergencia extraordinaria que escapen al control del Estado y perjudiquen considerablemente la situación financiera o la sostenibilidad económica o social del Estado, apreciadas por la mayoría absoluta de los miembros del Congreso de los Diputados».

La sostenibilidad social, a priori, parece una noción muy amplia, aunque no vacía de contenido, pudiéndose entender que se perjudica considerablemente a la sostenibilidad social cuando el mantenimiento de la estabilidad presupuestaria implique medidas regresivas de prestaciones sociales que, desde una perspectiva singular, impliquen afectaciones del núcleo mínimo inviolable de derechos sociales, o sea a su contenido esencial (lo que supondría que en este caso se debería excepcionar el límite de déficit y respetar dicho mínimo blindado) y comprometan la sostenibilidad o cohesión social de la sociedad española. 
Ahora bien, si queremos hablar seriamente sobre sostenibilidad social, tal como señala Ponce, debe mejorarse la calidad normativa por lo que se refiere a la especificación de este concepto, estableciéndose indicadores lo más precisos posibles de cuando una crisis económica perjudica considerablemente a la sostenibilidad social (indicadores relativos a niveles de desempleo, entre otros, por ejemplo $)^{58}$.

4. Tal como ya se ha señalado, el Tribunal Constitucional ha sido errático a la hora de establecer qué se entiende por medidas regresivas de derechos sociales y cuáles son los límites de las mismas y no ha sido capaz de fijar una doctrina sobre este asunto, pues en algunas sentencias parece proclive a defender la teoría de la irreversibilidad del contenido legislativamente fijado de los derechos sociales y en otras no.

En todo caso, el Tribunal Constitucional no ha avalado la existencia de un principio de progresividad de los derechos en nuestro ordenamiento jurídico, o incluso ha admitido regresiones sin buscar una suficiente justificación constitucional para ellas ${ }^{59}$, lo que ha adquirido una especial relevancia en los últimos años en los que desde el comienzo de la crisis económica las medidas regresivas a nivel legislativo han aumentado en nuestro país, afectando de modo negativo a los derechos sociales.

Por todo ello, dado que la jurisprudencia constitucional ha parecido no tomar en consideración las exigencias del principio de no regresividad de los derechos sociales emanados del Derecho internacional, se hace preciso, pues, reconocerlo de forma expresa en la Constitución, en concreto añadiendo un nuevo apartado al artículo 53, con mención a los elementos del modelo de control de las medidas regresivas que se acaban de citar.

5. Este nuevo apartado del artículo 53 de la Constitución española incluiría el siguiente contenido e incluso podría formularse así o de modo análogo:

Todas las medidas normativas que supongan una regresión en el contenido, eficacia, protección y garantía de los derechos de ámbito socioeconómico:

a) Deberán justificarse plenamente en referencia a la totalidad de los derechos, valores y principios recogidos en la Constitución y en los tratados internacionales suscritos por el Estado español y en el contexto del aprovechamiento pleno del máximo de los recursos de que se disponga.

b) Se aplicarán tras el examen más exhaustivo de todas las alternativas posibles.

58 Op. cit., p. 118.

59 Véanse SSTC 184/1993, 197/2003, 44/2004, 213/2005 o 128/2009. 
c) Tendrán en todo caso carácter temporal hasta que las circunstancias económicas permitan restablecer el ámbito material de contenido, eficacia, protección y garantía prexistente de los derechos sociales afectados.

d) En todo caso respetarán el contenido mínimo esencial de los derechos sociales como manifestación de la dignidad bumana.

e) Serán razonables y estarán suficientemente motivadas.

f) No vulnerarán, entre otros, los principios de seguridad jurídica, confianza legítima, no discriminación e irretroactividad de disposiciones restrictivas de derechos individuales.

g) Respetarán los principios de solidaridad, cohesión y sostenibilidad social.

b) A la hora de su aprobación se ha de justificar que las medidas adoptadas pretendan un fin constitucionalmente legítimo y sean proporcionadas, debiéndose demostrar además que con carácter previo se han adoptado medidas que bayan supuesto restricciones en otros gastos no supeditados a la eficacia de mandatos constitucionales específicos de indole social.

Title:

The principle of non-regressivity of Social rights in the Spanish Constitutional Law.

\section{Summary}

1. State, solidarity and social cohesion. 2. Doctrinal and jurisprudential notes on the principle of non-regressivity of social rights. 3. Limits to the regressivity of social rights. a) Limits derived from international law. b) Limits derived from dignity as essential content of social rights. c) Limits derived from the prohibition of arbitrariness: the need for sufficient motivation. 4. Conclusion: constitutional amendment and non-regressivity of social rights.

\section{Resumen:}

Este trabajo analiza la situación en el modelo constitucional español del principio de no regresividad de los derechos sociales. Se parte del análisis sucinto del modelo social de nuestra Constitución lo que implica el reconocimiento de derechos económicos y sociales. Este reconocimiento es la plasmación constitucional de los principios de solidaridad y de cohesión social. El principio de cohesión social ha sido definido por el Consejo de Europa e incluido explícitamente en los tratados 
constitutivos de la Unión Europea. La necesidad de lograr la cohesión social fundamenta la inclusión en las Constituciones y en los tratados internacionales del principio de no regresividad de los derechos sociales. En la Constitución española de 1978 este principio no se incluye expresamente. La no inclusión en la Constitución de este principio supone un peligro para la cohesión social en tiempos de crisis económica. Por su parte, el Tribunal Constitucional ha sentado una doctrina ambigua sobre este asunto, que ha sido analizada en este trabajo, así como las más significativas aportaciones doctrinales sobre la materia. Para saber cuáles son los limites de la regresividad de los derechos sociales que dotan de contenido este principio se ha realizado una comparativa internacional y de los principios constitucionales. Del estudio del ordenamiento internacional y de los valores y principios constitucionales se ha obtenido una serie de límites a la regresividad del contenido, eficacia y protección de los derechos sociales. Concluye este trabajo sugiriendo una propuesta de reforma constitucional que incluya el principio de no regresividad de los derechos sociales en el texto constitucional estableciendo una serie de requisitos de aquellas medidas que puedan suponer una regresión de contenido de los mismos tales como que deberán justificarse plenamente en referencia a la totalidad de los derechos, valores y principios recogidos en la Constitución y en los tratados internacionales suscritos por el Estado español y en el contexto del aprovechamiento pleno del máximo de los recursos de que se disponga; se aplicarán tras el examen más exhaustivo de todas las alternativas posibles; tendrán en todo caso carácter temporal hasta que las circunstancias económicas permitan restablecer el ámbito material de contenido, eficacia, protección y garantía prexistente de los derechos sociales afectados; en todo caso respetarán el contenido mínimo esencial de los derechos sociales como manifestación de la dignidad humana; serán razonables y estarán suficientemente motivadas; no vulnerarán, entre otros, los principios de seguridad jurídica, confianza legítima, no discriminación e irretroactividad de disposiciones restrictivas de derechos individuales, serán proporcionadas y respetarán los principios de solidaridad, cohesión y sostenibilidad social.

\begin{abstract}
:
This paper analyzes the constitutional recognition of the principle of non - regressivity of social rights in Spain. It starts from the succinct analysis of the social model of our Constitution which implies the recognition of economic and social rights. This recognition is the constitutionalization of the principles of solidarity and social cohesion. The principle of social cohesion has been defined by the Council of Europe and explicitly included in the constitutive treaties of the
\end{abstract}


European Union. The need to achieve social cohesion underpins the inclusion in the Constitutions and international treaties of the principle of non-regression of social rights. In the Spanish Constitution of 1978 this principle is not expressly included. The non-inclusion in the Constitution of this principle poses a danger to social cohesion in times of economic crisis. For its part, the Constitutional Court has established an ambiguous doctrine on this subject, which has been analyzed in this work, as well as the most significant doctrinal contributions on the subject. In order to know which are the limits of the regressivity of the social rights that give content of this principle an international comparison has been made as well as a study of constitutional principles. Limits to the regressivity of content, effectiveness and protection of social rights have been obtained from the study of international order and constitutional values and principles. This paper concludes by suggesting a proposal for constitutional amendment that includes the principle of non-regressivity of social rights in the Spanish Constitution establishing some requirements of those measures that imply a regression of their content such as: they shall be fully justified in relationship with all the rights, values and principles contained in the Constitution and in the international treaties signed by the Spanish State and in the context of full exploitation of the maximum resources available; Shall be applied after a more comprehensive examination of all possible alternatives; Shall in any case be of a temporary nature until the economic circumstances permit the restoration of the content, effectiveness, protection and pre-existing guarantee of the social rights affected; In any case they will respect the essential minimum content of social rights as a manifestation of human dignity; Shall be reasonable and sufficiently motivated; Shall not infringe, inter alia, the principles of legal certainty, legitimate expectations, non-discrimination and non-retroactivity of provisions restricting individual rights; Shall be proportionate and shall respect the principles of solidarity, cohesion and social sustainability.

\section{Palabras clave:}

Estado social; Cohesión social; Principio de no regresividad de los derechos sociales; Reforma constitucional.

\section{Key words:}

Welfare state; Social cohesion; Principle of non-regressivity of social rights; Constitutional amendment. 